\title{
2012 National Capital Area Branch Seminar
}

\author{
23-24 AUGUST 2012 \\ Gaylord National Hotel and Convention Center \\ National Harbor, MD
}

The National Capital Area Branch (NCAB) of the American Association for Laboratory Animal Science (AALAS) held its annual seminar 23-24 August in National Harbor, MD. The theme of this year's seminar, "Maximizing the Value and Impact of Animal Care," was reflected in the topics for the breakout sessions and poster presentations. The importance of maintaining cleanliness in animal facilities was emphasized in several presentations, covering topics such as techniques for aseptically transferring rodents from the cage and rack to the biosafety cabinet or animal transfer station; an overview of IVCs; design, principles and practice of biosafety cabinets; and a review of different mopping systems. Several sessions discussed the use of unique animal species, including the breeding and caretaking of a thicket rat research colony; the use of Drosophila melanogaster in neuroscience research; raising puppies as canine companions for independence or service dogs; and health assessment of Florida manatees in the wild. Other sessions addressed facility management topics like adjusting to change in the workplace, management strategies for new supervisors, managing the budgeting process, teaching motivational skills to staff and use of research management systems to improve workflows and data collection. Interactive educational activities included the Tech Fun Fair, in which laboratory animal technicians competed to show off their biomedical research knowledge.

Twenty posters were presented at the seminar. The Grand Prize was awarded to "Techniques for digital nerve block in rhesus macaques (Macaca mulatta) by Zachary A. Myles of Advanced BioScience Laboratories, Inc. Other winning posters included “Tech got your tongue': pharyngeal aspiration inoculation as a viable alternative for lung inoculations in mice" by S. Bonner of Sobran, Inc. (1st place); "Use of novel telemetry devices to collect individually discernible data sets from socially housed rhesus macaques" by Shannon A. Stutler \& D.M. Cox of US Army Medical Research Institute of Chemical Defense (2nd place); "Using the modified puppy aptitude test to aid in breeder selection at a canine production facility" by Carol Shepherd, J. Spencer and B. Rohr (3rd place); and "African thicket rats: improved method of husbandry and breeding" by J.A. Hinderer of NIAID (4th place and Audience Vote award). Good Effort awards were given to "Does the method of feeding calorie restricted mice have any impact on long term data results?" by D. Boyer et al.; "Raising mutant zebrafish larvae utilizing saltwater rotifers" by M. Wisnieski II; and "Physiological changes associated with physotigmine as a nerve agent

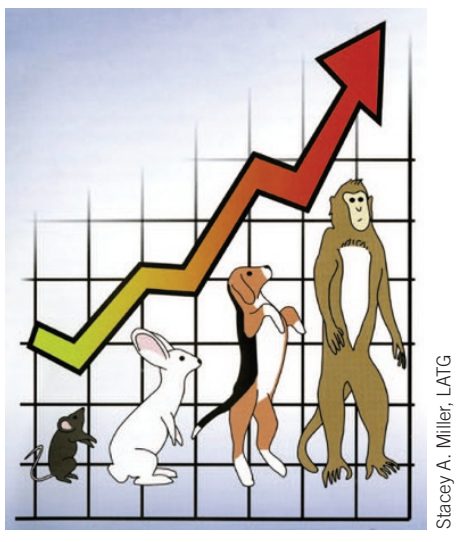

simulant" by D.M. Cox \& Shannon A. Stutler of US Army Medical Research Institute of Chemical Defense. Other awards went to "Working safely with animals in ABSL-3/4" by Stacey A. Miller et al. of Battelle National Biodefense Institute (Best Image); "Isoflurane safety is all about proper scavenging" by B. Wilgenburg (Most Educative); and "Barbering patterns: is there a strain predilection?" by C. Chavez of Sobran, Inc. (Best Handout).

The Keynote Address, entitled "Gene therapy for canine leukocyte adhesion deficiency," was given by Dr. Thomas R. Bauer, Jr., scientist at the National Cancer Institute in Bethesda, MD. Dr. Bauer discussed his research on human leukocyte adhesion deficiency (LAD), a disease characterized by delayed umbilical cord separation, high white blood cell count, bacterial infections and impaired wound healing. He explained why canine LAD currently provides the most promising animal model for testing gene therapy approaches for human LAD. Not only do dogs provide a direct translational model to humans and have a long lifespan, allowing for long-term treatment follow-up, but they also share the genetic basis for the disorder, a defect in the leukocyte integrin molecule CD18. Dogs affected with LAD suffer from bacterial infections and reduced white blood cell counts. In an initial case study, 11 dogs were treated with gene therapy to replace cells with CD18+ cells to correct the genetic defect. Six of the dogs showed benefits of the gene therapy treatment, while five dogs failed to show any improvement. In a second study with an improved system for delivering the CD18+ cells, all dogs showed normalized white blood cell counts. This second study is currently the basis for preclinical trials for human therapies.

Several awards were given out at the seminar. Recipients included Leigh Hostetler, presented with the Charles G. Durbin Award; Marsha Sowers, presented with the Richard L. Pierson Award; Arturo Gyles, presented with the Dr. William I. Gay Award; and Dr. David Cox, presented with the Dr. Joseph R. Held Award. The NCAB Council awarded its Lifetime Achievement Award to Betty Fatzie, who has served the branch for more than 30 years. 